\title{
La Representación en Herbart y en Freud y su Lugar en la Enseñanza
}

\author{
Ana María Fernández Caraballo' \\ 'Facultad deHumanidadesyCiencias delaEducación(FHCE), Montevidéu-Uruguai \\ RESUMEN - La Representación en Herbart y en Freud y su Lugar en la En- \\ señanza. En este artículo se pretende dar cuenta de las diferentes nociones \\ de representación en la filosofía y psicología de J. F. Herbart y en la teoría \\ psicoanalítica de S. Freud. A partir de estas nociones se desplegará el lugar \\ que adquieren en la propuesta herbartiana sobre la enseñanza y en los con- \\ ceptos de saber y conocimiento en el contexto teórico freudiano. \\ Palabras-clave: Herbart. Freud. Representación. Enseñanza. Conocimiento.
}

ABSTRACT - Representation in Herbart and Freud and Its Place in Teaching. This article analyzes the different notions of representation in the philosophical and psychological theories of J. F. Herbart as well as ind the psychoanalytic theory of S. Freud. It thereby explores the functions these notions have in the Herbartian teaching theory and in the Freudian theories of knowing ande knowledge.

Keywords: Herbart. Freud. Representation. Teaching. Knowledge.

Educação \& Realidade, Porto Alegre, v. 38, n. 3, p. 747-767, jul./set. 2013.

Disponível em: <http://www.ufrgs.br/edu_realidade> 
La Representación en Herbart y en Freud y su Lugar en la Enseñanza

\section{Presentación}

Johann Friedrich Herbart, filósofo, psicólogo y pedagogo alemán del siglo XIX fue alumno de Fichte, enseñó en la Universidad de Göttingen hasta cerca de su muerte. La obra de dicho autor es muy prolífera y en su tiempo contó con una importante aprobación de sus postulados pedagógicos. Sus ideas fueron utilizadas desde Franz Brentano, Gustav Adolf Lidner, Franz Exner hasta John Dewey. También influyó en filósofos y psicólogos posteriores en el tiempo e incluso en las primeras teorizaciones de S. Freud.

A nivel filosófico se destacan los textos Filosofía Práctica Universal (1808) e Introducción a la Filosofía (1813). Se dedica un tiempo a postular principios dentro de la incipiente psicología, de ahí escritos tales como la Psicología como Ciencia (1824) y el Manual de Psicología (1816). El interés por la pedagogía surgió a partir de la visita que le realizó en Suiza a Pestalozzi entre 1797 y 1800, de allí surgen, entre otros, los libros Pedagogía General (1806) y el Bosquejo de Lecciones de Pedagogía (1835)ํ․

Se ha señalado con insistencia que la noción de representación freudiana se basó en las fuentes teóricas de la psicología y filosofía herbartiana. Ahora bien, ¿cómo se produce dicha filiación teórica y epistemológica?, ¿qué aspectos sobre dicha noción se mantienen y cuáles se modifican? Herbart no solamente le aporta a Freud su idea de representación, junto con ellas se encuentran, entre otras, nociones tales como la de conflicto, yo, conciencia, inconsciente, deseo, represión, que serán reformuladas en el contexto teórico del psicoanálisis.

Dividiremos el artículo en dos partes, por un lado, desplegaremos las conceptualizaciones herbartianas sobre la representación y su lugar en la enseñanza y, por otro lado, daremos cuenta de las propuestas freudianas sobre la representación y de allí derivaremos en la diferenciación que se establece entre conocimiento y saber en alguno de sus textos.

\section{Sobre la Noción de Representación en Herbart y su Lugar en la Enseñanza}

La noción de representación (Vorstellung) en Herbart se encuentra elaborada, fundamentalmente, en dos de sus libros: el Manual de Psicología (Lehrbuch zu Psychologie) donde enuncia el objeto propio de la Psicología y en La Psicología como Ciencia, Fundada en la Experiencia, la Metafísica y la Matemática (Psychologie als Wissenschat, neu gegründet aufErfahrunge, Metaphysisk und Mathematik) donde continúa y profundiza su postulados psicológicos.

Como indica Bréhier (1956, p. 412) la doctrina de Herbart es una doctrina de entendimiento (Verstand). En su Manual de Psicología (1964a, p. 178) entiende que "[...] no será posible liberarse de la condición fundamental de la Verstehen, que es el reconocimiento de las contradicciones dadas en las formas de la experiencia”. 
En el texto Sobre el Lado Oscuro de la Pedagogía (Über die dunkle Seite der Pädagogik) de 1812 entiende que los datos de la experiencia son contradictorios y por lo tanto no son la realidad. Para el autor la filosofía consiste en buscar las realidades verdaderas que conducen a tales experiencias, cuando se las ha limpiado de contradicciones (Herbart, 1964b, p. 394). Es más, comienza por un escepticismo concerniente a los conceptos fundamentales:

\begin{abstract}
[...] cada cosa debe ser una, y resalta que, en cambio, percibimos una multiplicidad de cualidades de ella; se afirman lazos de causa a efecto entre los acontecimientos, y sólo se percibe una sucesión; se afirma la unidad del yo, y sólo se capta una multiplicidad de representaciones; la contradicción herbartiana está, por tanto, entre lo dado y lo pensado como real (Bréhier, 1956, p. 413).
\end{abstract}

La realidad es dada inmediatamente y solamente se conoce, a través de los fenómenos, algunos caracteres generales de ella. Es más, en su libro Pedagogía General entiende que el sujeto vive en el seno de relaciones y no hay necesidad de otra cosa (Herbart, 1935).

Sustituye el concepto de propiedades inherentes a una sustancia, que es contradictorio, por el concepto de relación accidental de un ser simple con otros seres simples, cuya coexistencia no indica necesidad respecto al primero, y que hacen de todas las pretendidas propiedades, meros accidentes:

También se explica así el yo y la multiplicidad de sus representaciones; si estas representaciones - como dice Fichte - fuesen inherentes al yo, en virtud de un límite que le sería propio el yo resultaría una unidad múltiple; en realidad el sujeto es un ser simple; la serie de los actos por los que pone objetos, es una serie de actos de conservación de sí mismo contra los esfuerzos de los otros seres para destruirlo, y ha nacido, por tanto, de relaciones accidentales con los otros seres. Este procedimiento constituye el 'método de relaciones' que Herbart opone al espíritu de la filosofía reinante (Bréhier, 1956, p. 413-414).

El surgimiento de la filosofía de Herbart consistió en resolver las contradicciones con que se encontró Fichte:

Al tratar de deducir el No-Yo del Yo, principio primero, Fichte se enfrenta al problema de la oposición del Yo y del No-Yo en el Yo. De ahí, Herbart traslada el problema al interior del propio Yo: 'En verdad, partí del estudio del Yo' declara en el Prefacio de su Psicología (Assoun, 1982, p. 135).

Para resolver la contradicción de la identidad del sujeto y el objeto descompone la supuesta unidad en una multiplicidad de representaciones. "La dinámica representacional proviene de las contradicciones" (Assoun, 1982, p. 130). 
La Representación en Herbart y en Freud y su Lugar en la Enseñanza

Aplicado al problema central del yo, el método lógico lleva a situar el origen del sujeto en el antagonismo de las representaciones que se destruyen mutuamente; el yo se reduce, al cabo de esa dialéctica resuelta, a un lugar vacío (leere Stelle), centro común (Mittel-punkt) o punto de cruce de las representaciones (Erkreuzungspunkt der Vorstellungen). Así, éstas tienen la doble función de materializar la fragmentación del sujeto y de determinarlo [...] las representaciones no constituyen las propiedades del psiquismo, que estaría 'compuesto de representaciones'. [...] cada representación explota como fuegos artificiales, de tal modo que la representación manifiesta tanto el Yo como su disipación (Assoun, 1982, p. 137).

Para Herbart toda masa de representaciones se compone de complexiones de representaciones, si la compexión es total van y vienen de la conciencia como un todo indiviso, y de series de representaciones con asociación. Éstas se desarrollan sucesivamente y por partes, cuando no son perturbadas.

La estructura interna de la masas aisladas de representaciones se llega a conocer cuando los pensamientos se manifiestan en palabras [...] en las masas de representaciones no hay que pensar simplemente en lo representado, sino también en el estado del espíritu (Herbart, 1945, p. 25).

En el capítulo Grados de la Instrucción de su Pedagogía General entiende que una representación adquiere fuerza "[...] por el poder de la impresión sensible" o por la eficacia de las descripciones y, sobre todo, “[...] por la existencia en el fondo del alma de representaciones afines que se unen ahora con las nuevas" (Herbart, 1935, p. 142).

La masa de representaciones existentes nacen de dos fuentes principales: la experiencia y el trato social. De la experiencia proceden los conocimientos de la naturaleza, "[...] pero en una forma discontinua y tosca". Por su parte, del trato social, derivan los sentimientos hacia los hombres, "[...] pero no siempre de un modo plausible, sino con frecuencia en una forma censurable" (Herbart, 1945, p. 29-30).

Además, su psicología consiste en la aplicación de su metafísica y se vincula a una teoría del conocimiento. Es más, para el autor la psicología es una investigación de las leyes matemáticas de ese conflicto dinámico de las representaciones. "Muestra cómo desemboca tal conflicto en la fusión (Verschmelzung) de representaciones homogéneas y su reproducción" (Bréhier, 1956, p. 414).

El alma es una sustancia simple que tiende a autoconservarse. Cada representación es un acto particular por el cual el alma se conserva. Oponiéndose a la teoría de las facultades señala que no hay sino representaciones. Los hechos psicológicos son representaciones y el alma sólo se actualiza en el modo de representación. La psique es factible de investigación científica desde el momento en que la misma tiene su átomo o representación.

750 Educação \& Realidade, Porto Alegre, v. 38, n. 3, p. 747-767, jul./set. 2013 Disponível em: <http://www.ufrgs.br/edu_realidade> 
Ahora bien, el primer carácter visible de las representaciones es que, como fuerzas, son susceptibles de medición. La primera intuición del psiquismo para Herbart consiste, pues, en la idea de una dinámica cuantificable, o sea un cambio de fuerzas y de oscilaciones susceptibles de más y de menos, de un contraste de grados muy preciso (Assoun, 1982, p. 130).

Las representaciones de la misma naturaleza se oponen mutuamente y tienden a destruirse entre sí. Si una representación encuentra la oposición de otra más poderosa se opaca haciéndose cada vez menos consciente hasta que resulta rechazada. Como resultado no puede extinguirse y queda fuera de la conciencia, se transforma en tendencia:

Las representaciones idénticas se oponen unas a otras y dicha oposición es factible de radicalizarse en resistencia (Widerstand). El resultado del conflicto es que tal o cual representación sea reprimida (Verdrängung) por otra. Herbart llama la detención o inhibición (Hemmung) al proceso mediante el cual la representación se ve limitada en y por su oposición a otra. De hecho el resultado de la detención es separar la representación en dos partes: una que se transforma en 'tendencia', otra que subsiste como residuo (Rest) más o menos debilitado. Se define entonces por cierto grado (Grad) de oscurecimiento (Verdunkelung) de la representación (Assoun, 1982, p. 132).

También el afecto (Affekt) es un hecho psíquico que está en el mismo plano que la representación. Como indica Bréhier (1956, p. 414):

La psicología herbartiana es una investigación de las leyes matemáticas de ese conflicto dinámico de las representaciones. [...] Los fenómenos afectivos no son una especie aparte, sino que nacen también de este conflicto de representaciones; el dolor viene de que una representación (por ejemplo, la de un amigo perdido) es a la vez atraída (verbigracia, por la representación de los lugares en que lo habíamos encontrado) y rechazada (por la representación de su muerte).

En el libro Pedagogía General (1935, p. 253) entiende que las experiencias son confirmaciones de una convicción psicológica simple:

[...] que todos los sentimientos son sólo modificaciones pasajeras de representaciones existentes; que, por lo tanto, cuando cesa la causa modificadora, el círculo de ideas ha de volver a adquirir por sí mismo su antiguo equilibrio.

Para Assoun (1982, p. 131) hay una física de las representaciones en Herbart, en la medida en que las representaciones permanecen en estado de equilibrio cuando alcanzan el grado de obscurecimiento (Verdunkelung) exigido por su oposición. Evoca dicho oscurecimiento progresivo de las representaciones como un movimiento de caída. En base a ello surge la idea de una estática y de una mecánica del espíritu. 
La Representación en Herbart y en Freud y su Lugar en la Enseñanza

\begin{abstract}
No es fortuito que la consideración de la dinámica representacional desemboque en Herbart en la implicación del inconsciente en la vida psíquica. Una representación está en la conciencia en la medida en que no está sometida a la 'detención'. El proceso de oscurecimiento [...] pasa en cierto grado por un umbral (Schwelle), definido como el estado de representación en que la menor acción basta para traerla a la conciencia - lo cual, tópicamente, sería comparable al sistema preconsciente en Freud (Assoun, 1982, p. 132).
\end{abstract}

Herbart se adelanta de una manera muy inicial a la relación entre la conciencia y el inconsciente. El campo de la conciencia es estrecho y por lo tanto no todas las representaciones pueden estar presentes simultáneamente. Ocupan la conciencia únicamente las percepciones actuales y las imágenes a ellas relacionadas. Las demás representaciones son rechazadas por la conciencia y pueden ser extraídas a partir de nuevos nexos asociativos.

La vida psíquica no podría ser sino un collar de representaciones. Cuando dos representaciones de índole diferente se unen, Herbart habla de composición (Complexion); cuando se trata de representaciones de índole idéntica, hay fusión (Schmelzung). A partir de esa doble combinatoria básica, se abre una verdadera lógica de la reproducción representativa. [...] La asociación no se efectúa por una simple contigüidad como en el asociacionismo clásico: se basa en un acontecimiento cuyo resultado es modificar la dinámica global de las representaciones (Assoun, 1982, p. 132).

Ahora bien, ¿̇qué lugar ocupan las representaciones en la conceptualización herbartiana sobre la enseñanza?

En el Bosquejo para un Curso de Pedagogía (1945, p. 9) entiende que la pedagogía general es estudiada acorde a los tres conceptos capitales del gobierno, la instrucción y la disciplina. La instrucción (que Herbart llama didáctica) es incierta en cuanto a la forma de ser recibida y elaborada. Para reducir dicha incertidumbre se hace necesario cuidar el "estado de espíritu del alumno para que sea adecuado a la instrucción. Ésta es la misión de la disciplina”. Por su parte, en el texto Pedagogía General (1935, p. 63) considera por instrucción todo aquello que se presenta al alumno como objeto de estudio, comprende la disciplina misma a la cual se le somete.

Llenar el espíritu (Ausfüllung des Gemüts) es el objeto general que debe surgir de la instrucción. Non scholae, sed vital discendum! No enseñar para la escuela, sino para la vida! (Herbart, 1935, p. 201-202)

Además, con la disciplina se pueden "[...] prevenir las pasiones y evitar las explosiones masivas de los afectos” (Herbart, 1945, p. 32). La disciplina colabora con la instrucción ya que facilita el "temprano de- 
sarrollo de las mejores emociones del individuo, con lo cual llegarán éstas a predominar" (Herbart, 1945, p. 33). Por su parte, el fundamento del gobierno consiste en mantener ocupados a los niños, evitar el desorden: “[...] la infancia raramente sabe mantenerse ocupada de un modo satisfactorio y continuo". A las ocupaciones se "[...] une la vigilancia y, a ella, mandatos y prohibiciones múltiples” (Herbart, 1945, p. 39).

Un gobierno que quiera satisfacer sus fines sin educar oprime el espíritu, y una educación que no se preocupa del desorden de los niños demostrará su desconocimiento hasta de los mismos niños (Herbart, 1935, p. 76).

El gobierno de los niños cuenta con medios auxiliares que preparan sus almas: la autoridad y el amor. La autoridad doblega el espíritu y el amor descansa sobre la armonía de los sentimientos y la certidumbre.

El concepto fundamental de la pedagogía es la educar al alumno y “[...] la educabilidad de la voluntad para la moralidad sólo la reconocemos en el hombre” (Herbart, 1935). Es más,

[...] la pedagogía, como ciencia, depende de la filosofía práctica y de la psicología. La primera da cuenta del fin de la educación y la segunda el camino, los medios y los obstáculos (Herbart, 1945, p. 9).

Es interesante señalar cómo en el capítulo II La educación propiamente dicha de su Pedagogía General (1935, p. 94-95) presenta la "unidad del fin pedagógico". Dicha unidad no puede derivarse de la naturaleza misma de la cosa, más bien hay que partir de la siguiente idea: el educador se representa en el niño el hombre futuro. Por lo tanto sus esfuerzos consisten en encaminar en el presente los fines que el alumno tendrá en el futuro como adulto. Lo más elevado que puede hacer la humanidad en cada momento de su vida es "[...] presentar concentradamente a la generación joven el beneficio de sus ensayos anteriores, bien sea como enseñanza, bien sea como advertencia" (Herbart, 1935, p. 54-55).

El fin supremo de la educación es la moralidad. Como plantean Reale y Antiseri (1988, p. 202-203), en lo que se refiere a la pedagogía, la moral es la que establece sus objetivos, mientras que la psicología fija sus medios. Al comienzo de su propia existencia el alma humana no tiene ideas, ni está dotada de apriorismos ni de facultades.

El alma inicialmente sólo está dotada de una fundamental tendencia a la autoconservación. Está, bajo el estímulo de las realidades externas, reacciona ante ellas formando sus propias representaciones. Basado en estas convicciones, Herbart considera la educación como un fenómeno de asimilación por parte del espíritu, 'el cual, carente de contenido original suyo, todo lo adquiere a través de la paulatina experiencia del mundo de la naturaleza o a través de las relaciones espirituales con los demás hombres que viven en sociedad'. Al principio el espíritu no

Educação \& Realidade, Porto Alegre, v. 38, n. 3, p. 747-767, jul./set. 2013.

Disponível em: <http://www.ufrgs.br/edu_realidade> 
La Representación en Herbart y en Freud y su Lugar en la Enseñanza

es bueno ni malo, y puede volverse según las influencias externas que reciba, una u otra cosa. Se comprende así la importancia que asume la figura del maestro en la pedagogía de Herbart.

Es importante que el educador observe cuáles son las representaciones que surgen más fácil o más difícil y si permanecen en la conciencia o desaparecen. Esto es condición para la eficacia de la instrucción y la disciplina. Si en la instrucción se presentan solamente conocimientos, no se puede garantizar en modo alguno si con ello puede oponerse un contrapeso importante a los defectos de la individualidad y a las masas de representaciones que existen independientemente de aquéllas. "Pero de la influencia en esas masas depende el qué y el cuándo puede adquirirse por la instrucción para la moralidad” (Herbart, 1945, p. 28).

El educador tiende a lo general mientras que el alumno es un individuo particular. Enseñar implica conciliar la individualidad con el carácter y la multiplicidad:

[...] la individualidad es inconsciente, es la raíz oscura de donde muestro presentimiento psicológico cree ver brotar lo que se manifiesta en el hombre en forma distinta según las circunstancias (Herbart, 1935, p. 105).

Educar hacia la perfección significa una formación armoniosa del sujeto y generar una estructuración lo más sólida posible de la masa aperceptiva, suministrando gradualmente las representaciones más oportunas. Esta tendencia de la masa aperceptiva a agregar nuevas representaciones es para Herbart el interés. Los intereses dependen de las representaciones que cada sujeto posee y se vuelven cada vez más activas. Provocar nuevas representaciones que no sean efímeras consiste en influir sobre los intereses. Los intereses resultan de las fuerzas de atracción o repulsión que poseen las diversas representaciones.

El interés tiene como punto de partida los objetos y las ocupaciones interesantes. De la riqueza de ambos surge el interés múltiple. Producir y presentar convenientemente esta riqueza es el objeto de la instrucción [...] (Herbart, 1935, p. 109).

El interés, el deseo, la voluntad y el juicio estético se oponen a la indiferencia. Ahora bien, el objeto del interés nunca puede ser el mismo que el del deseo

Pues el deseo, en cuanto puede concebir, aspira a algo futuro, que no posee aún; por el contrario el interés se desarrolla en el intuir y se adhiere todavía a lo intuido como presente (Herbart, 1935, p. 109).

Herbart considera que el mejor modo para conseguir cultivar el interés consiste en centralizar la enseñanza alrededor de un centro que provoque una activa participación afectiva. El maestro llegará incluso a 
ser para el discípulo un "[...] objeto de experiencia tan rico como inmediato", entre ellos se establecerá "un verdadero trato social” (Herbart, 1935, p. 125).

\title{
Sobre la Representación Freudiana y su Relación con el Conocimiento y el Saber
}

La conceptualización sobre la representación (Vorstellung) en Freud - así como el recorrido durante su obra - ha sido estudiada en profundidad por muchos autores ${ }^{2}$. Nuestro interés en este punto consiste en plantear las bases principales sobre dicho concepto para luego derivar en un posible planeamiento sobre el conocimiento y el saber que se desprende a partir de dicha noción.

Como ya hemos indicado, el modelo freudiano se nutre de la tradición de la psicología alemana que se remonta a los principios del siglo XIX con Herbart. A modo de muestra encontramos que para Strachey (1996a, p. 156), en la Nota introductoria a Lo inconsciente, desde los inicios del pensamiento freudiano el concepto de inconsciente no encontraba resistencias en el medio que lo rodeaba. Es más,

\begin{abstract}
Los maestros inmediatos de Freud (por ej. Meyner) se regían fundamentalmente, hasta donde llegaba su interés por la psicología, por los puntos de vista de J. F. Herbart (1776-1841); y parece ser que en la escuela secundaria a la que asistió Freud se utilizaba un libro de texto que contenía los principios herbartianos [...]. El reconocimiento de la existencia de procesos anímicos inconscientes desempeñaba un papel esencial en el sistema de Herbart.
\end{abstract}

Algo similar plantea respecto de la represión en la Nota introductoria al texto de Freud sobre esa noción:

El término 'Verdrängung' ya había sido utilizado por Herbart, psicólogo de comienzos del siglo XIX, y probablemente llegó a conocimiento de Freud a través de su maestro Meynert, quien era un admirador de Herbart [...] (Strachey, 1996b, p. 138).

No obstante, en el texto Contribución a la Historia del Movimiento Psicoanalítico de 1914, Freud (1996a, p. 15) declaró que "[...] la doctrina de la represión es ahora el pilar fundamental sobre el que descansa el edificio del psicoanálisis, su pieza más esencial”. Es más, dice: “[...] es seguro que la concebí yo independientemente; no sé de ninguna influencia que me haya aproximado a ella, y durante mucho tiempo tuve a esta idea por original”. Más adelante, en 1925, en su Presentación Autobiográfica (Freud, 1996b, p. 138) escribió: “[...] era una novedad, nunca se había discernido en la vida anímica nada que se le pareciese”3.

En la misma línea se ubica Etcheverry (1996, p. 16) cuando señala que de todo teórico es posible rastrear sus antecedentes, sin embargo 
La Representación en Herbart y en Freud y su Lugar en la Enseñanza

aquello que importa es la síntesis lograda y las nuevas articulaciones con las categorías preexistentes que consiguen tener una nueva significación:

Nos situamos fuera del rastreo de antecedentes en ese sentido trivial, parcial. Empero, más allá de lo que pueda entenderse por 'cultura', es difícil creer que un pensador de lengua alemana, en la vuelta del siglo XIX al XX, no estuviera inmerso en el pensamiento clásico alemán. Este último opera en Freud como una sustancia cultural dada, desde la cual articula lo novedoso de su creación. Si es ocioso buscar 'antecedentes' en el afán de negar lo original de un pensamiento, es imposible discernir eso nuevo si no se lo recorta contra el fondo de su contexto histórico.

Por su parte, para Assoun (1982, p. 135) cuando Freud ubica en la base de la actividad psíquica la representación reconstruye el proyecto herbartiano.

[...] Herbart no lega simplemente a Freud algunas herramientas conceptuales, le trasmite cierta concepción del conocimiento mismo basado en problemáticas metafísicas. [...] Al tomar posesión del herbartismo, se apropia de cierta concepción, implícita pero eficaz, de la objetivad y de la psique. Por lo tanto no sería sorprendente observar la presencia implícita de esas categorías en la metapsicología freudiana [...].

Ahora bien, en la obra de Freud la representación cobra diversos estatutos. El mismo se encuentra desde los inicios de su producción teórica y se irá complejizando en el transcurso de sus elaboraciones. Comienza en el trabajo sobre La Afasia (Zur Auffassung der Aphasien, 1891), continúa en el Proyecto de Psicología (1895) y en los textos Metapsicológicos como La Represión (1915), Lo Inconsciente (1915) y Pulsiones y Destinos de la Pulsión (1915) ${ }^{4}$.

En La Afasia (1973, p. 90) ya presenta la diferenciación esencial entre representación palabra (Wortvorstellung) y representación cosa o de objeto (Sachvorstellung).

La representación de objeto aparece así como una representación no cerrada, apenas capaz de serlo, mientras que la representación palabra aparece como algo cerrado, aun si parece capaz de extensión.

Si bien ambas representaciones están ligadas dando lugar a la significación, dicha ligadura “[...] se opera esencialmente entre la faz visual de la representación de objeto y la imagen sonora de la representación palabra" (Le Gaufey, 2012, p. 125). En el Apéndice C-Palabra y Cosa del artículo Lo Inconsciente, Freud (1996c, p. 197-198) entiende que:

Lo que pudimos llamar representación-objeto (Objektvorstellung) conciente se nos descompone ahora en represen- 
tación-palabra (Wortvorstellung) y en la representación-cosa (Sachvorstellung), que consiste en investidura, si no de la imagen mnémica directa de la cosa, al menos de huellas mnémicas más distanciadas, derivadas de ellas.

Las investiduras de las huellas corresponden sólo a las relaciones entre las representaciones objeto, pero, a diferencia de las imágenes, no representan a los objetos con sus cualidades sensibles.

Mientras que la imagen mnémica (término heredado de Wernike) re-presenta la cosa, es el calco más o menos deformado de acontecimientos y objetos de los que conserva ciertas particularidades sensibles, y puede ser investida en lugar de la cosa (realización alucinatoria del deseo), la huella mnémica, también deriva de la cosa, no es más que el signo de su poder de estímulo, del quantum de energía que la cosa ha movilizado, pero no conserva ninguna cualidad sensible. Más que un representante, es un residuo (Enaudeau, 1999, p. 142-43).

Respecto de la representación palabra, Freud (1996c, p. 211) conserva la expresión tomada de la neurofisiología que había usado en el texto La Afasia.

La palabra es, pues, una representación compleja, que consta de las imágenes que hemos consignado; expresado de otro modo: corresponde a la palabra un complejo asociativo, en el que confluyen los elementos de origen visual, acústico, kinestésico [...]. Ahora bien, la palabra cobra significado por su enlace con la 'representación-objeto' [...].

Para Enaudeau (1999, p. 146-47) esta diferenciación entre representación palabra y representación de objeto presenta dos problemas. En el texto Lo Inconsciente aparece el primero:

Las representaciones-palabra, provienen, por su parte, de la percepción sensorial de igual manera que las representaciones-cosa, de suerte que podría plantearse esta pregunta: ¿Por qué las representaciones-objeto no pueden devenir conscientes por medio de sus propios restos de percepción? (Freud, 1996c, p. 198-99).

Una posible respuesta se encuentra en el texto de 1923 El Yo y el Ello (Freud, 1996d, p. 23):

[...] casi siempre es el material concreto (konkret) de lo pensado lo que deviene conciente, pero, en cambio, no puede darse expresión visual a las relaciones que distinguen particularmente a lo pensado. Por tanto, el pensar en imágenes es sólo muy imperfecto devenir-conciente. Además, de algún modo más próximo a los procesos inconscientes que el pensar en palabras, y sin duda alguna es más antiguo que éste, tanto ontogenética como filogenéticamente.

Educação \& Realidade, Porto Alegre, v. 38, n. 3, p. 747-767, jul./set. 2013. 
La Representación en Herbart y en Freud y su Lugar en la Enseñanza

La actividad inconsciente sería esencialmente visual, hecha de imágenes mnémicas ópticas. Éstas sólo se volverán conscientes por conexión con las representaciones de palabras correspondientes y son las únicas “[...] capaces de traducir relaciones, de expresar un verdadero pensamiento” (Enaudeau, 1999, p. 147).

Por su parte, el segundo problema se encuentra en el artículo de 1911 "Formulación sobre los dos Principios del Acaecer Psíquico" (Freud, 1996e, p. 226):

Es probable que en su origen el pensar fuera inconsciente, en la medida en que se elevó por encima del mero representar y se dirigió a las relaciones entre las impresiones de objeto; entonces adquirió nuevas cualidades perceptibles para la conciencia únicamente por la ligazón con los restos de palabra.

Además de la imagen visual inconsciente que representa a la cosa, conserva sus cualidades sensibles y puede ser investida en lugar de ella, "[...] habría un pensamiento inconsciente, una red de relaciones" (Enaudeau, 1999, p. 148).

Ahora bien, en el Proyecto de Psicología (Freud, 1996f) parte de un principio:

[...] a partir de una especie de tabula rasa buscará construir paso a paso un aparato apropiado para dar cuenta de los múltiples datos clínicos clasificados por él como 'psicológicos' (Le Gaufey, 1998, p. 218).

La representación está presente desde el primer capítulo, cuando Freud plantea que la "concepción cuantitativa" que va a exponer

Está extraída directamente de observaciones patológicoclínicas, en particular aquellas en que se trata de unas representaciones hiperintensas, como en la histeria y en la neurosis obsesiva, donde, como se demostrará, el carácter cuantitativo resalta con más pureza que en el caso normal. Procesos como estímulo, sustitución, conversión, descarga, sugirieron de una manera directa la concepción de la excitación neuronal como cantidades fluyentes (Freud, 1996f, p. 339-40).

Más adelante dirá que el yo puede caer en aflicción cuando un "estado de deseo" invista de nuevo el "objeto-recuerdo":

[...] entonces decreta la descarga, no obstante que la satisfacción por fuerza faltará, porque el objeto no tiene presencia real sino sólo en una representación-fantasía Freud, 1996f, p. 370).

La representación se diferencia de la imagen-recuerdo por el hecho de que el objeto real que representa no está allí, la percepción no la encuentra. 
Las 'representaciones hiperintesas' no se comprenden si no se las refiere a otras representaciones reprimidas. La represión cae sobre representaciones y éstas se vuelven 'incompatibles' con otras representaciones investidas conscientemente por el yo (Le Gaufey, 1998, p. 223).

Como señala Le Gauffey (1998) la idea de una representación reprimida está en los comienzos de la producción freudiana. Lo esencial de la represión es quebrar la sutura representación/afecto, y en reprimir la representación que debe ser localizada en el inconsciente. En el artículo Lo Inconsciente plantea que

El psicoanálisis nos ha enseñado que la esencia del proceso de represión no consiste en cancelar, en aniquilar una representación representante de la pulsión, sino de impedirle que devenga consciente. Decimos entonces que se encuentra en el estado de lo 'inconsciente', y podemos ofrecer buenas pruebas de que aún así es capaz de exteriorizar afectos, incluidos los que finalmente alcanzan la conciencia (Freud, 1996c, p. 161).

Aparece en escena el término Representante de la representación (Vorstellungsrepräsentanz) ligado a lo pulsional: "No podemos aludir sino a una moción pulsional cuyo representante de la representación es inconsciente pues otra cosa no entra en cuenta" (Freud, 1996c, p. 173).

Y, en el artículo sobre La Represión (Freud, 1996g, p. 143) se establece la diferenciación entre la Vorstellung y la Vortellungsrepresäsentanz. La dinámica de la represión comienza por la de una represión primordial (Urverdrängung):

Pues bien; tenemos razones para suponer una represión primordial, una primera fase de la represión que consiste en que a la agencia representante (Representanz) psíquica (agencia representante-representación) de la pulsión se le deniega la admisión en lo conciente. Así se establece una fijación; a partir de ese momento la agencia representante en cuestión persiste inmutable y la pulsión sigue ligada a ella.

La representación es para Freud uno de los dos elementos del proceso psíquico, el otro es el afecto (Affekt), traducción de la cantidad de energía pulsional. De hecho, no es un hecho psíquico en el mismo plano que la representación: “[...] el quantum de afecto (Affektbetrag) es un elemento integrante del proceso psíquico que es fundamentalmente representacional" (Assoun, 1982, p. 135).

En el texto de 1926 Psicoanálisis se lee la filiación de Freud con esa psicología de las fuerzas. Dirá que el psicoanálisis “[...] reconduce todos los proceso psíquicos [...] al juego de las fuerzas que se promueven o inhiben unas a otras, se conectan entre sí, entran en compromisos, etc." (Freud, 1996h, p. 253). 
La Representación en Herbart y en Freud y su Lugar en la Enseñanza

Como indica Le Gaufey (2006, p. 228) se produce una ecuación: representación + monto de afecto $=$ representante.

Entonces el Representante psíquico, que se designa por Repräsentanz, Vorstellungs-repräsentanz o Triebrepräsentanz, está compuesto por una representación y por un monto de afecto que lo diferencia de los destinos que la represión obliga a distinguir.

En Pulsiones y Destinos de la Pulsión (Freud, 1996i) ya se lee que la Vorstellungsrepräsentanz retoma y continúa la Triebrepräsentanz (representante de la pulsión): la pulsión, concepto límite entre lo psíquico y lo somático, no tiene algo que le corresponda directamente en el psiquismo. Entre estos dos elementos dispares existe una soldadura que va a funcionar como representante de dicha pulsión.

Surge entonces la necesidad de hacer aparecer este nuevo compuesto que es la representación 'suturada' a una energía pulsional y ese será el representante de la representación. Es decir, una representación no sólo investida por el yo sino abarrotada con una cantidad suplementaria, el monto de afecto (Le Gayfey, 2006, p. 230).

Junto a la percepción consciente - en la cual el mensaje sensorial se limita a rozar la superficie de los órganos de los sentidos y es reenviado al punto de donde viene para separarse de la cosa y representarla - el registro inconsciente

[...] se imprime por el contrario en profundidad y fija en la huella mnémica una moción desencadenada por la estimulación, moción que con su empuje continuo aliena el psiquismo a una realidad (Wirklichkeit) que no cesa de actuar (wirken) y de la cual él nunca tuvo representación. Esquema pregnante del objeto inconsciente, cuyo representante, lejos de liberarnos, confirma su poder (Enaudeau, 1999, p. 142).

La incapacidad de impermeabilidad de los estímulos físicos y la capacidad de permeabilidad de las imágenes inmateriales de las cosas da cuenta de un doble funcionamiento del sistema sensorial que no hace más que traducir la doble polaridad de las pulsiones.

Unirse y separarse es el poder contradictorio que da autoridad a la percepción y al lenguaje; el poder de convertir las cosas en representación, de retener de ellas solamente su aspecto (tanto el visible como el inteligible) [...] (Enaudeau, 1999, p. 141).

A partir de la pulsión y el lenguaje es posible encontrar una vía de conceptualización freudiana sobre el conocimiento y el saber.

En la teoría freudiana, la noción de saber se encuentra íntimamente relacionada con su estudio sobre la teoría de las pulsiones y, en particular, con la curiosidad de saber (Wissbegierde) y la investigación sexual 
infantil. Se puede leer el recorrido que realiza Freud en el transcurso de su obra sobre la Pulsión de Investigar o Pulsión de Saber al menos en los siguientes textos: Tres Ensayos de Teoría Sexual (1905), El Esclarecimiento Sexual del Niño (1907), Sobre las Teorías Sexuales Infantiles (1908), Análisis de la Fobia de un Niño de Cinco Años (1909) y Un Recuerdo Infantil de Leonardo Da Vinci (1910) ${ }^{5}$.

En 1905 en Tres Ensayos de Teoría Sexual, la temática se encuentra vinculada con lo que Freud denomina la "curiosidad sexual infantil". En el apartado La investigación sexual infantil plantea que

\begin{abstract}
A la par que la vida sexual del niño alcanza su primer florecimiento entre los tres y cinco años, se inicia en él también aquella actividad que se adscribe a la pulsión de saber o de investigar. La pulsión de saber no puede computarse entre los componentes pulsionales elementales ni subordinarse de manera exclusiva a la sexualidad. Su acción corresponde, por una parte, a una manera sublimada del apoderamiento y, por la otra, trabaja con la energía de la pulsión de ver (Freud, 1996j, p. 176-77).
\end{abstract}

La pulsión de saber de los niños es precoz e intensa y despierta por los "problemas sexuales" que se le presentan. Relaciona dicha pulsión con el resto de las pulsiones, indicando que no se trata de una pulsión parcial en sí sino que trabaja con la energía de las pulsiones de apoderamiento y de ver. Como plantea Behares (2008, p. 15):

En la escritura de la pulsión, Freud es capaz de hacer una distinción fundamental. Por un lado, constituye la figura referida a la dimensión de conocimiento, o sea la representación establecida y estable, lograda por 'el ser bueno, pero también la suspensión del reflexionar' ante ella, ante la demanda enseñante del adulto, que constituye en su terminología la dimensión de lo 'consciente'. Por otro, abre la posibilidad de un saber cuyos orígenes están en una substracción a ese influjo, mediante 'el trabajo de investigación', que 'ha aportado entretanto nuevas pruebas que no deben tener vigencia', y que, por tanto, 'deviene sofocada, 'inconsciente". Esta bifurcación se da como una verdadera escisión psíquica, que constituye al sujeto y a su vida anímica.

En El Esclarecimiento Sexual del Niño (Freud, 1996k, p. 117) continúa su teorización sobre la pulsión de saber o investigar. Entiende que “[...] el interés intelectual del niño por los enigmas de la vida genésica, su apetito de saber sexual, se exterioriza en una época de la vida inesperadamente temprana”. El primer problema que se le plantea al niño es el "enigma” de la diferencia de los sexos. “¿De dónde vienen los niños? Es una desfiguración que es fácil deshacer, es éste el mismo enigma que proponía la Esfinge de Tebas" (Freud, 1996j, p. 177). El segundo problema que atarea el pensar de los niños es el de los orígenes de la vida. Entiende que ésta es la pregunta más antigua de la vida infantil. Afirma que:

Educação \& Realidade, Porto Alegre, v. 38, n. 3, p. 747-767, jul./set. 2013. 761

Disponível em: <http://www.ufrgs.br/edu_realidade> 
La Representación en Herbart y en Freud y su Lugar en la Enseñanza

Las respuestas usuales en la crianza de los niños menoscaban su honesta pulsión de investigar, y casi siempre tienen como efecto conmover por primera vez su confianza en sus progenitores; a partir de ese momento, en la mayoría de los casos empiezan a desconfiar de los adultos y a mantenerles secretos sus intereses más íntimos (Freud, 1996k, p. 119).

Y, en Sobre las Teorías Sexuales Infantiles (Freud, 1996l, p. 190) reafirma su idea de que, al comienzo, el niño parece preguntarse, casi siempre a partir del nacimiento de algún hermanito, “[...] la pregunta misma, como todo investigar, es un producto del apremio de la vida, como si al pensar se le planteara la tarea de prevenir la recurrencia de un suceso tan temido".

El niño crea sus propias teorías sexuales, las cuales tienen un "curioso carácter", a primera vista parecen "grotescamente falsas", sin embargo cada una de ellas "contiene un fragmento de verdad" y

[...] son análogas en este aspecto a las soluciones tildadas de 'geniales' que los adultos intentan para los problemas del universo cuya dificultad supera el intelecto humano. Lo que hay en esas teorías de correcto y acertado se explica por su proveniencia de los componentes de la pulsión sexual, ya en movimiento dentro del organismo infantil. En efecto, tales supuestos no han nacido del albedrío psíquico ni de unas impresiones casuales, sino de las objetivas necesidades de la constitución psicosexual (Freud, 1996l, p. 192).

Dicho "fragmento de verdad" encierra "la dimensión propia del saber". Para el niño, entonces, "[...] el saber se constituye en el lugar de su falta y de su demanda insatisfecha" (Behares, 2008, p. 8).

Ahora bien, el pensar del niño puede emanciparse pronto de su incitación y puede continuar su trabajo como una pulsión autónoma de investigar. Es decir que este interés se independizaría del fin práctico del cual surge, para dirigirse al conocimiento del mundo en general. Como indica Behares (2008, p. 7), por un lado, el niño se enfrenta a las “[...] urgencias de la vida, a las necesidades egoístas de su pulsión, a su Lebensnot, y, por otro, a las respuestas insuficientes y a las inhibiciones provenientes del mundo adulto". Entre estas dos tensiones "[...] se instaura el Wissbegierde. Para Freud esta posibilidad funda una escisión psíquica". En palabras de Freud (1996l, p. 191).

Desde este conflicto psíquico puede desenvolverse pronto una 'escisión psíquica'; una de las opiniones, la que conlleva el ser bueno, pero también la suspensión del reflexionar, deviene la dominante, consciente; la otra, para la cual el trabajo de investigación ha aportado entretanto nuevas pruebas que no deben tener vigencia, deviene sofocada, 'inconsciente'. 
En el caso sobre el pequeño Hans (Análisis de la Fobia de un Niños de Cinco Años, Freud, 1996m) entiende que el apetito de saber y la curiosidad sexual son inseparables entre sí. Para Freud hay una temprana madurez sexual en Hans y es intelectualmente despierto. Encuentra que dicha madurez sexual temprana constituye un "[...] correlato infaltable de los intelectuales, y por eso en niños dotados se la hallará con mayor frecuencia de lo que se esperaría” (Freud, 1999m, p. 114).

En una línea similar se encuentra el trabajo “Un Recuerdo Infantil de Leonardo Da Vinci [...]”, (Freud, 1996n, p. 69-70). Entiende que en este artista los afectos estaban sometidos a la pulsión de investigar:

No había hecho sino mudar la pasión en esfuerzo de saber; se consagraba a la investigación con la tenacidad, la constancia, el ahondamiento que derivan de la pasión, y en la cima del trabajo intelectual, tras haber ganado el conocimiento, dejaba que estallara el afecto largamente retenido, que fluyera con libertad como un brazo desviado del río después que él culminaba la obra.

En este trabajo Freud (1996n, p. 74) plantea que si la investigación sexual infantil es clausurada por la represión sexual el destino de la pulsión de investigar tiene tres posibilidades derivadas del temprano enlace con intereses sexuales: el primer destino se produce cuando "[...] la investigación comparte el destino de la sexualidad" limitando o inhibiendo el apetito de saber, el segundo se da cuando el desarrollo intelectual resiste la represión sexual, entonces “[...] la investigación sexual sofocada regresa de lo inconsciente como compulsión a cavilar", y el tercero, que Freud califica de "raro y perfecto", sucede cuando escapa tanto a la inhibición del pensar como a la compulsión neurótica del pensamiento. La libido escapa al destino de la represión “[...] sublimándose desde el comienzo mismo en su apetito de saber y sumándose como refuerzo a la vigorosa pulsión de investigar”. Leonardo sería el prototipo de este tercer tipo.

Ahora bien, ¿cuáles son las vías de teorización sobre el conocimiento en la epistemología freudiana? En Esquema del Psicoanálisis, Freud (1996o) señala que en el estudio del aparato psíquico hacemos las observaciones por medio de las lagunas que lo anímico presenta. Esa expresión laguna (Lücke) se encuentra desde sus primeros trabajos. Es más, lo psíquico es "lagunoso”, es decir, su concatenación presenta desgarramientos.

Partiendo del principio del determinismo universal, es preciso postular, entonces, la noción de lo psíquico inconsciente. Sigue manifestando Freud: completamos lo que falta mediante inferencias evidentes, y lo traducimos a un material conciente. Recuérdese que 'traducciones' se operaban de manera espontánea en el aparato psíquico. Esta 'traducción' de la ciencia obedece, como no podría ser de otro modo, al funcionamiento mismo del aparato.

Educação \& Realidade, Porto Alegre, v. 38, n. 3, p. 747-767, jul./set. 2013.

Disponível em: <http://www.ufrgs.br/edu_realidade> 
La Representación en Herbart y en Freud y su Lugar en la Enseñanza

Y la traducción se hace a lo conciente: 'Así establecemos una serie complementaria (Ergänzungsreihe) conciente respecto de lo psíquico inconsciente' (Etcheverry, 1996, p. 39-40).

La posición que Freud mantiene desde el Proyecto de Psicología (Freud, 1996f) consiste en que el conocimiento conciente es concienteinconsciente, desde el momento en que obedece a leyes dadas por la estructura misma del aparato cognoscente. Evidentemente, el estado de cosas por conocer no es él mismo conciente, entonces se hace necesario traducirlo a representación conciente, ya que no es posible conocer la cosa en sí.

Recordemos que tanto la palabra como el objeto son representaciones (representación-palabra y representación-objeto) y que la representación no espeja un objeto, sino que ella misma lo es. No obstante, es necesario indicar que

[...] el uso no puede ser estricto en Freud, puesto que el objeto-representación se constituye por referencia a las cosas del mundo, a lo que está ahí, enfrente; y, entonces, 'objeto’ (Objekt) designará a veces ‘objeto del mundo'. Pero lo importante es retener que en Freud resuena la tradición kantiana para la cual la representación es síntesis pues supone algo dado en la sensación, ligado por la actividad del entendimiento (Etcheverry, 1996, p. 24-25).

En el texto ya citado “Esquema del Psicoanálisis” Freud (1996o, p. 126) entiende que lo real permanecerá siempre incognoscible. Es necesario inteligir nexos presentes en el mundo exterior.

Hemos dado versión sistemática de 'inteligir’ (einsehen) e 'intelección' (Einsicht). Es que tienen un valor preciso. Se aproximan a una intuición intelectual de nexos del mundo real. Ésta es fruto de alguna actividad de conocimiento, puesto que lo real sólo nos es dado en la percepción. No percibimos en sentido estricto tales nexos; en cierto modo los 'vemos' con el intelecto. Ahora bien, la tarea de la ciencia es reproducir o espejar esos nexos, esas tramas de lo real, en el mundo interior de nuestro pensamiento. Y tener noticia (Kenntnis) de ellos 'nos habilita para comprender algo en el mundo exterior' (Etcheverry, 1996, p. 40).

Además, entiende que intercalamos los procesos inconscientes con los uns bewusst, con aquello que nos resulta notorio, sabido, consabido, familiar, aquello de que tenemos conciencia.

Y decimos: Aquí ocurrió algo para nosotros inaprehensible (Unfassbares). Si hubiera llegado a la conciencia, lo habríamos descrito así y así. Y en realidad, varios pasajes del libro sobre los sueños terminan, tras el análisis de un proceso psíquico, con su traducción en palabras. Tam- 
bién es común la fórmula 'en el inconsciente se dice' (es heisst), que parece ser una anticipación verbal del Es, el ello, posterior. $Y$ 'dice' es el intento de traducir en palabras lo no dicho (Etcheverry, 1996, p. 40-41).

Conocer consiste en descifrar las propiedades de la cosa. El sujeto quiere lograr alcanzar cierta percepción que le despertaría la satisfacción, pero percibe algo que no es idéntico al recuerdo que tiene de la cosa que percibió simultáneamente a una satisfacción anterior. La desemejanza provoca el proceso de comparación, de descomposición de complejo perceptivo que Freud denomina "examen de realidad" de forma tal de discernir aquello que es nuclear y realizar los actos que lo conduzcan a la satisfacción. Al decir de Etcheverry (1996, p. 42) allí se encuentra una relación de correspondencia. Ya desde el Proyecto de psicología es posible inferir que el yo discierne núcleos o residuos que son incognoscibles "[...] en las cosas del mundo, porque él mismo tiene un núcleo”. A partir de la segunda tópica, “[...] el yo, desde su núcleo, discierne como el núcleo de su ser al oscuro ello” (Etcheverry, 1996, p. 42).

Recebido em 29 de abril de 2013 Aprovado em 27 de maio de 2013

\section{Notas}

1 Las fechas que figuran entre paréntesis corresponden a la primera edición. Sobre esta temática ver: Bréhier, 1956 y Reale y Antiseri, 1988.

2 A modo de ejemplo remitimos a los trabajos de Assoun, 1982; Le Gaufey, 1998; 2006; 2012; Strachey, 1996a; 1996b; Etcheverry, 1996.

3 Sobre esta temática ver: Strachey, 1996b, p. 138.

4 Las fechas que figuran entre paréntesis corresponden a la versión original.

5 Las fechas que figuran entre paréntesis corresponden a la versión original.

\section{Referencias}

ASSOUN, Paul-Laurent. Introducción a la Epistemología Freudiana. Buenos Aires: Siglo XXI editores, 1982.

BEHARES, Luis Ernesto. Enseñar en Cuerpo y Alma: la teoría de la enseñanza y el saber en la pulsión. Educação Temática Digital, Cuerpo, lenguaje y enseñanza, Campinas, v. 8, p. 1-21, jun. 2007. Disponible en: <http://143.106.58.55/revista/viewissue.php?id=24>. Acceso en: 20 feb. 2013.

BRÉHIER, Émile. Historia de la Filosofía. Tomo III. Buenos Aires: Editorial Sudamericana: 1956.

ENAUDEAU, Corinne. La Paradoja de la Representación. Buenos Aires: Paidós, 1999.

ETCHEVERRY, José Luis. Sobre la Versión Castellana. In: STRACHEY, James. Obras Completas de Sigmund Freud. Buenos Aires: Amorrortu editores, 1996. P. 1-141. 
La Representación en Herbart y en Freud y su Lugar en la Enseñanza

FREUD, Sigmund. Contribución a la Historia del Movimiento Psicoanalítico. In: STRACHEY, James. Obras Completas de Sigmund Freud. Buenos Aires: Amorrortu editores, 1996a, Tomol4. P. 1-64.

FREUD, Sigmund. Presentación Autobiográfica. In: STRACHEY, James. Obras Completas de Sigmund Freud. Buenos Aires: Amorrortu editores, 1996b, Tomo 20. P. 1-70.

FREUD, Sigmund. Lo Inconsciente. In: STRACHEY, James. Obras Completas de Sigmund Freud. Buenos Aires: Amorrortu editores, 1996c, Tomo 14. P. 153-162.

FREUD, Sigmund. El Yo y el Ello. In: STRACHEY, James. Obras Completas de Sigmund Freud. Buenos Aires: Amorrortu editores, 1996d, Tomo 19. P. 1-66.

FREUD, Sigmund. Formulación sobre los dos Principios del Acaecer Psíquico. In: STRACHEY, James. Obras Completas de Sigmund Freud. Buenos Aires: Amorrortu editores, 1996e, Tomo 12. P. 217-32.

FREUD, Sigmund. Proyecto de Psicología. In: STRACHEY, James. Obras Completas de Sigmund Freud. Buenos Aires: Amorrortu editores, 1996f, Tomo 1. P. 333-441.

FREUD, Sigmund. La Represión. In: STRACHEY, James. Obras Completas de Sigmund Freud. Buenos Aires: Amorrortu editores, 1996g, Tomo 14. P. 135-152.

FREUD, Sigmund. Psicoanálisis. In: STRACHEY, James. Obras Completas de Sigmund Freud. Buenos Aires: Amorrortu editores, 1996h, Tomo 20. P. 247-258.

FREUD, Sigmund. Pulsiones y Destinos de Pulsión. In: STRACHEY, James. Obras Completas de Sigmund Freud. Buenos Aires: Amorrortu editores, 1996i, Tomo 14. P. 105-134.

FREUD, Sigmund. Tres Ensayos de Teoría Sexual. In: STRACHEY, James. Obras Completas de Sigmund Freud. Buenos Aires: Amorrortu editores, 1996j, Tomo 7. P. 109-224.

FREUD, Sigmund. El Esclarecimiento Sexual del Niño. In: STRACHEY, James. Obras Completas de Sigmund Freud. Buenos Aires: Amorrortu editores, 1996k, Tomo 9. P. 111-222.

FREUD, Sigmund. Sobre las Teorías Sexuales Infantiles. In: STRACHEY, James. Obras Completas de Sigmund Freud. Buenos Aires: Amorrortu editores, 1996l, Tomo 9. P. 183-202.

FREUD, Sigmund. Análisis de la Fobia de un Niño de Cinco Años. In: STRACHEY, James. Obras Completas de Sigmund Freud. Buenos Aires: Amorrortu editores, 1996m, Tomo 10. P. 1-118.

FREUD, Sigmund. Un Recuerdo Infantil de Leonardo Da Vinci. In: STRACHEY, James. Obras Completas de Sigmund Freud. Buenos Aires: Amorrortu editores, 1996n, Tomo 11. P. 53-128.

FREUD, Sigmund. Esquema del Psicoanálisis. In: STRACHEY, James. Obras Completas de Sigmund Freud. Buenos Aires: Amorrortu editores, 1996o, Tomo 23. P. $133-210$.

FREUD, Sigmund. La Afasia. Buenos Aires: Edición Nueva Visión, 1973.

HERBART, Johann Friedrich. Lehrbuch zu Psychologie (Manual de Psicología). In: KEHRBACH, Karl; OTTO, Flug (Org.). Johann Friedrich Herbart, Sämtliche Werke (Johann Friedich Herbart, Obras completas). Tomo IV. [S.I.: S.n.], 1964a. Disponible en: <http://books.google.com.uy/books/about/Joh_Fr_Herbart_s_ sämtliche_Werke>. Acceso en: 10 mar. 2013. 
HERBART, Johann Friedrich. Über die dunkle Seite der Pädagogik (Sobre el lado oscuro de la pedagogía). In: KEHRBACH, Karl; OTTO, Flug (Org.). Johann Friedrich Herbart, Sämtliche Werke (Johann Friedich Herbart, Obras completas). Tomo III. [S.l.: S.n.], 1964b. Disponible en: <http://books.google.com.uy/books/ about/Joh_Fr_Herbart_s_sämtliche_Werke>. Acceso en: 10 mar. 2013.

HERBART, Johann Friedrich. Psychologie als Wissenschat, neu gegründet auf Erfahrunge, Metaphysisk und Mathematik (La Psicología como ciencia, fundada en la experiencia, la metafísica y la matemática). Köningsber: Gebrüdern Bornträger, 1922. Disponible en: <http://books.google.com>. Acceso en: 10 mar. 2013.

HERBART, Johann Friedrich. Pedagogía General. Derivada del fin de la educación. Madrid, Espasa-Calpe, 1935.

HERBART, Johann Friedrich. Bosquejo para un Curso de Pedagogía. Madrid, Espasa-Calpe, 1945.

LE GAUFEY, Guy. El lazo Especular. Buenos Aires: Edelp, 1998.

LE GAUFEY, Guy. Representación Freudiana y Significante Lacaniano. In: LE GAUFEY, Guy. El Caso Inexistente. Una compilación clínica. México: Peele, 2006.

LE GAUFEY, Guy. La Incompletud de lo Simbólico. Buenos Aires: Letra Viva, 2012.

REALE, Giovanni; ANTISERI, Dario. Historia del Pensamiento Filosófico y Científico. Tomo III. Del Romanticismo hasta hoy. Barcelona: Editorial Herder, 1988.

STRACHEY, James. Nota Introductoria a Lo Inconsciente. In: STRACHEY, James. Obras Completas de Sigmund Freud. Buenos Aires: Amorrortu editores, 1996a, Tomo14. P. 155-159.

STRACHEY, James. Nota Introductoria a La Represión. In: STRACHEY, James. Obras Completas de Sigmund Freud. Buenos Aires: Amorrortu editores, 1996b, Tomol4. P. 137-39.

Ana María Fernández Caraballo es licenciada en Psicología y en Lingüística, Magíster en Psicología y Educación, Psicoanalista. Directora de la Línea de Investigación "Enseñanza y Psicoanálisis" (Departamento de Enseñanza y Aprendizaje, Instituto de Educación, F.H.C.E., UdelaR, MontevideoUruguay).

E-mail:amfernandezcaraballo@gmail.com 